\title{
The Relationship Between the Side-Lying Endurance Test and Ultrasound Thickness Measurement for Abdominal Muscles
}

\author{
Morteza Taghipour ${ }^{1}$; Fatemeh Rajabzadeh ${ }^{1}$; Amir Massoud Arab ${ }^{1, *}$ \\ ${ }^{1}$ Department of Physical Therapy, University of Social Welfare and Rehabilitation Sciences, Tehran, IR Iran \\ *Corresponding author: Amir Massoud Arab, Department of Physical Therapy, University of Social Welfare and Rehabilitation Sciences, Tehran, IR Iran. Tel: +98-21 22180039, Fax: \\ +98-2122180039, E-mail:arabloo_masoud@hotmail.com
}

Received: August 16, 2014; Accepted: December 24, 2014

Background: Low Back Pain (LBP) is a common musculoskeletal disorder in the different societies.

Objectives: The purpose of this study was to investigate the relationship between the side-lying endurance test and ultrasound thickness measurement of the anterolateral abdominal muscles.

Patients and Methods: A convenience sample of 55 subjects, aged 20 - 30 years, participated in this study. Endurance of abdominal muscles was measured using side-lying endurance test in all subjects. Ultrasound thickness measurement for the Transverses Abdominis (TVA), Internal Oblique (IO), and External Oblique (EO) muscles was performed on the right side at rest in supine position.

Results: The results of the Pearson correlation coefficient between the variables of the study showed no significant relationship between the side-lying endurance test and ultrasound thickness measurements of TVA $(r=0.06, P=0.65), \operatorname{IO}(r=0.06, P=0.62)$, and EO $(r=0.08, P=$ $0.54)$ muscles. The significance level of 0.05 was chosen.

Conclusions: It seems that there is no significant relationship between the side-lying endurance test and abdominal muscles thickness.

Keywords: Ultrasound Imaging; Abdominal Muscles; Lying

\section{Background}

Low back pain (LBP) is a common musculoskeletal disorder in different societies (1-3). Abdominal muscles endurance has been commonly associated with LBP. Anterolateral abdominal muscles are considered as postural muscles and trunk stabilizers (4). The Transverses Abdominis (TVA), Internal Oblique (IO), and External Oblique (EO) muscles compose a muscle cylinder, which provides the lumbar stability (5-7). Considerable evidence indicates abdominal muscle activity in patients with LBP (6, 8-12). Also, several studies have shown decreased abdominal muscles endurance in patients with $\operatorname{LBP}(4,13)$. Assessment of trunk muscle endurance has a greater discriminative validity than evaluation of muscle strength $(14,15)$ and is considered as one of the important causes of LBP (16). Measurement and monitoring of the abdominal muscles activity seems to be very important in clinical setting. Several clinical types of static endurance tests have been used to assess the trunk muscles endurance (17-21).

Side-lying endurance test is commonly used to assess endurance of anterolateral abdominal wall muscles in clinics (19-21). Ultrasound imaging is a reliable technique to assess muscle structure, function, and activity. It is particularly useful for deep muscles such as deep anterolateral abdominal muscles (22-24). The reliability of this method has been shown before (22). Furthermore, to assess its validity, several studies have compared ultra- sound measurements with magnetic resonance imaging (MRI) and electromyography (EMG) (25). Extensive studies have assessed the thickness of deep anterolateral abdominal muscle in subjects with LBP and have shown changes in the thickness of abdominal muscles in the subjects with LBP (26-29).

\section{Objectives}

The purpose of this study was to investigate the relationship between side-lying endurance test and ultrasound thickness measurement of the abdominal muscles.

\section{Patients and Methods}

Fifty-five healthy people aged 20 - 30 years ( 25 male, 30 female) participated in the study. Subjects were included in the study if they had no history of LBP, spinal surgery, spinal or pelvic fracture, hospitalization for severe trauma or injuries from a car accident, osteoarthritis or fracture of the lower extremities as well as any systemic diseases such as arthritis or tuberculosis. Before participating in the study, all subjects signed an informed consent form approved by the human subjects committee at the University of Social Welfare and Rehabilitation Sciences. Then, all participants filled out a simple health questionnaire. 


\subsection{Testing Procedures}

An ultrasound imaging B-mode unit (Ultrasonix-ES500, Canada) with a $3.5 \mathrm{MHz}$ linear head transducer was used to measure the thickness of the abdominal muscles (TVA, IO, and EO) at rest $(12,23-25,28,29)$. The measurements were made on the right side of the abdominal wall in supine position. The lumbar spine was positioned in neutral posture. The ultrasound transducer was located in transverse position across the abdominal wall over the anterior axillary line in the middle between the $12^{\text {th }}$ rib and the iliac crest. The cursor points measured the muscle thickness between the facial bands in ultrasound. The image was frozen on the screen and the muscle thickness was measured in millimeter by the marker (Figure 1 ). The participants were relaxed and examiner took 3 images of abdominal muscles at rest, and the mean value was used for the analysis.

\subsection{Side-Lying Endurance Test}

In this test, the subject was positioned in right sidelying. The superior hand is placed on the left side of the body and the inferior hand is placed on the floor. The subject was asked to raise both legs and maintain them as long as possible. The time was recorded in seconds, and the test was terminated when the subject can no longer maintain this condition.

\subsection{Data Analysis}

Kolmogorov-Smirnov test was utilized to assess the normality of the distribution for tested variables. Normal distribution was observed for variables. Pearson correlation coefficient was used to determine the correlation between ultrasound thickness measurement and side-lying endurance test for abdominal muscles. The significance level was set as 0.05 .

\section{Results}

Descriptive statistics for the subjects and measurement scores are presented in Table 1 . Table 2 presents the Pearson correlation coefficient between the variables. No significant relationship was found between the side-lying endurance test and the ultrasound thickness measurements of TVA $(\mathrm{r}=0.06, \mathrm{P}=0.65), \mathrm{IO}(\mathrm{r}=0.06, \mathrm{P}=0.62)$, and EO $(r=0.08, \mathrm{P}=0.54)$ muscles (Table 2$)$.

Figure 1. Ultrasound Measurement of the Abdominal Muscles Thickness

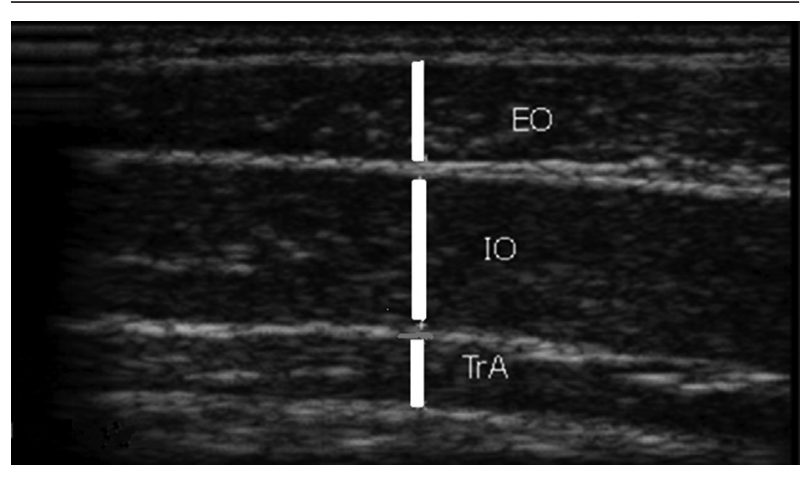

TVA, transverse abdominis; IO, internal oblique; EO, external oblique

\begin{tabular}{|c|c|c|c|}
\hline Variables & Mean \pm SD & Minimum & Maximum \\
\hline Age, $y$ & $21.37 \pm 1.37$ & 20.00 & 26.00 \\
\hline Weight, Kg & $66.51 \pm 13.87$ & 40.00 & 108.00 \\
\hline Height, cm & $169.24 \pm 9.87$ & 147.00 & 189.00 \\
\hline BMI, $\mathrm{Kg} / \mathrm{m}^{2}$ & $23.10 \pm 3.71$ & 17.07 & 33.33 \\
\hline US thickness for TVA, mm & $3.16 \pm 0.98$ & 1.53 & 6.13 \\
\hline US thickness for IO, mm & $6.09 \pm 2.39$ & 2.01 & 12.50 \\
\hline US thickness for EO, mm & $3.95 \pm 1.55$ & 1.59 & 9.35 \\
\hline Side-lying endurance, test (s) & $80.27 \pm 61.71$ & 15.00 & 274.00 \\
\hline
\end{tabular}

a Abbreviations: BMI, Body mass index; US, Ultrasound; TVA, Transverse abdominis; IO, Internal oblique; EO, External oblique; SD, Standard deviation.

Table 2. Pearson correlation Coefficient Between the Ultrasound Measurements and Side-Lying Endurance test for Abdominal Muscles $^{\mathrm{a}}$

\begin{tabular}{lccc}
\hline Variables & TVA Thickness & IO Thickness & EO Thickness \\
\hline Side-lying endurance test $(\mathbf{s})$ & & & \\
Pearson Correlation & 0.06 & 0.06 & 0.08 \\
PValue & 0.65 & 0.62 & 0.54 \\
\hline
\end{tabular}

a Abbreviations: TVA, Transverse abdominis; IO, Internal oblique; EO, External oblique. 


\section{Discussion}

The results of this study showed that there is no significant correlation between the side-lying endurance test and abdominal muscles thickness. Deep abdominal muscles are considered as postural muscles and primary stabilizers of the trunk to provide the stability of the lumbar spine during functions (4). Considering their anatomical, biomechanical, and physiological features, these muscles have slow twitch nature muscle fibers and are activated at low resistance levels ( $30 \pm 40 \% \mathrm{MVC}$ ), which are suitable for endurance activities.

Real-time ultrasound imaging has been recently used to evaluate muscle structure, thickness, function, and activation patterns. Ultrasound muscle thickness measurement is used to estimate muscle volume and strength. Ultrasound thickness of the TVA and IO muscles are commonly measured as an indicator of the abdominal muscle activity (22-24). The reliability of this method for measuring TVA muscle thickness has been established before (22). Validity studies have compared ultrasound measurements with those obtained using MRI or EMG (25). These findings support the use of ultrasound imaging as a non-invasive technique to measure abdominal muscle thickness and to approximate qualified muscle activity. Side-lying endurance test is commonly used to assess endurance of anterolateral abdominal wall muscles in clinics (19-21). Good sensitivity, specificity, and predictive value for abdominal muscles endurance tests in LBP have been reported both in males and females.

No significant relationship was found between the sidelying endurance test and the ultrasound thickness measurements of abdominal muscles. However, in this study subjects without LBP were not included and only healthy subjects participated. It is thought that side-lying endurance test assess the activity of the lateral section of the abdominal muscles. We found no relationship between the variables, as other muscles such as quadratus lumborum, hip abductors, and latissimus dorsi may contribute in performing side-lying test and abdominal muscles are not the only muscles which perform trunk side-flexion.

However, we acknowledge some limitations. One of the limitations of this study was the exclusion of the subjects with LBP. We suggest that this study is performed on the subjects with LBP to provide more insight regarding the relationship between ultrasound thickness measurement and side-lying endurance test for the abdominal muscles. Also, in this study, we disregard using EMG to monitor the activity of the different sections of the abdominal muscles during testing procedure. We suggest that this study could be done using EMG and ultrasonography.

\section{References}

1. Ehrlich GE. Low back pain. Bull World Health Organ. 2003;81(9):671-6.

2. Svensson HO, Andersson GB, Johansson S, Wilhelmsson C, Vedin A. A retrospective study of low-back pain in 38- to 64-year-old women. Frequency of occurrence and impact on medical services. Spine (Phila Pa 1976). 1988;13(5):548-52.
3. Woolf AD, Pfleger B. Burden of major musculoskeletal conditions. Bull World Health Organ. 2003;81(9):646-56.

4. Roy SH, De Luca CJ, Casavant DA. Lumbar muscle fatigue and chronic lower back pain. Spine (Phila Pa 1976). 1989;14(9):992-1001.

5. Bergmark A. Stability of the lumbar spine. A study in mechanical engineering. Acta Orthop Scand Suppl.1989;230:1-54.

6. Richardson C. Therapeutic exercise for spinal segmental stabilization in low back pain : scientific basis and clinical approach.Edinburgh, New York: Churchill Livingstone; 1999.

7. Hodges PW, Moseley GL. Pain and motor control of the lumbopelvic region: effect and possible mechanisms. J Electromyogr Kinesiol. 2003;13(4):361-70.

8. Jull GA, Richardson CA. Motor control problems in patients with spinal pain: a new direction for therapeutic exercise. J Manipulative Physiol Ther. 2000;23(2):115-7.

9. Hodges PW, Richardson CA. Delayed postural contraction of transversus abdominis in low back pain associated with movement of the lower limb.J Spinal Disord. 1998;11(1):46-56.

10. Hodges PW, Richardson CA. Inefficient muscular stabilization of the lumbar spine associated with low back pain. A motor control evaluation of transversus abdominis. Spine (Phila Pa 1976). 1996;21(22):2640-50.

11. Hides JA, Belavy DL, Cassar L, Williams M, Wilson SJ, Richardson CA. Altered response of the anterolateral abdominal muscles to simulated weight-bearing in subjects with low back pain. Eur Spine J. 2009;18(3):410-8.

12. Ferreira PH, Ferreira ML, Hodges PW. Changes in recruitment of the abdominal muscles in people with low back pain: ultrasound measurement of muscle activity. Spine (Phila Pa 1976). 2004;29(22):2560-6.

13. Ashmen KJ, Buz Swanik C, Lephart SM. Strength and flexibility characteristics of athletes with chronic low-back pain.J Sport Rehabil. 1996;5(4):275-86.

14. Biering-Sorensen F. Physical measurements as risk indicators for low-back trouble over a one-year period. Spine (Phila Pa 1976). 1984;9(2):106-19.

15. Kujala UM, Taimela S, Viljanen T, Jutila H, Viitasalo JT, Videman $\mathrm{T}$, et al. Physical loading and performance as predictors of back pain in healthy adults. A 5-year prospective study. Eur J Appl Physiol Occup Physiol. 1996;73(5):452-8.

16. Parnianpour M, Nordin M, Kahanovitz N, Frankel V. 1988 Volvo award in biomechanics. The triaxial coupling of torque generation of trunk muscles during isometric exertions and the effect of fatiguing isoinertial movements on the motor output and movement patterns. Spine (Phila Pa 1976). 1988;13(9):982-92.

17. Malliou P, Gioftsidou A, Beneka A, Godolias G. Measurements and evaluations in low back pain patients. Scand JMed Sci Sports. 2006;16(4):219-30.

18. Moreau CE, Green BN, Johnson CD, Moreau SR. Isometric back extension endurance tests: a review of the literature.J Manipulative Physiol Ther. 2001;24(2):110-22.

19. McIntosh G, Wilson L, Affieck M, Hall H. Trunk and lower extremity muscle endurance: normative data for adults. J Rehabil Outcome Meas. 1998;2(4):20-39.

20. Ito T, Shirado O, Suzuki H, Takahashi M, Kaneda K, Strax TE. Lumbar trunk muscle endurance testing: an inexpensive alternative to a machine for evaluation. Arch Phys Med Rehabil. 1996;77(1):75-9.

21. Moffroid MT. Endurance of trunk muscles in persons with chronic low back pain: assessment, performance, training.J Rehabil Res Dev. 1997;34(4):440-7.

22. Costa LO, Maher CG, Latimer J, Smeets RJ. Reproducibility of rehabilitative ultrasound imaging for the measurement of abdominal muscle activity: a systematic review. Phys Ther. 2009;89(8):756-69.

23. Teyhen DS, Gill NW, Whittaker JL, Henry SM, Hides JA, Hodges P. Rehabilitative ultrasound imaging of the abdominal muscles. $J$ Orthop Sports Phys Ther. 2007;37(8):450-66.

24. Henry SM, Westervelt KC. The use of real-time ultrasound feedback in teaching abdominal hollowing exercises to healthy subjects. J Orthop Sports Phys Ther. 2005;35(6):338-45.

25. McMeeken JM, Beith ID, Newham DJ, Milligan P, Critchley DJ. The 


\section{Taghipour M et al.}

relationship between EMG and change in thickness of transversus abdominis. Clin Biomech (Bristol, Avon). 2004;19(4):337-42.

26. Allison GT, Godfrey P, Robinson G. EMG signal amplitude assessment during abdominal bracing and hollowing. J Electromyogr Kinesiol. 1998;8(1):51-7.

27. Beith ID, Synnott RE, Newman SA. Abdominal muscle activity during the abdominal hollowing manoeuvre in the four point kneeling and prone positions. Man Ther. 2001;6(2):82-7.

28. Ainscough-Potts AM, Morrissey MC, Critchley D. The response of the transverse abdominis and internal oblique muscles to different postures. Man Ther. 2006;11(1):54-60.

29. Critchley DJ, Coutts FJ. Abdominal muscle function in chronic low back pain patients: measurement with real-time ultrasound scanning. Phys . 2002;88(6):322-32. 